\title{
Association of the $D$ repeat polymorphism in the ASPN gene with developmental dysplasia of the hip: a case-control study in Han Chinese
}

Dongquan Shi ${ }^{1,2+}$, Jin Dai ${ }^{1,2 \dagger}$, Pengsheng Zhu ${ }^{3}$, Jianghui Qin ${ }^{1}$, Lunqing Zhu' ${ }^{1}$, Hongtao Zhu ${ }^{3}$, Baocheng Zhao ${ }^{3}$, Xusheng Qiu', Zhihong Xu', Dongyang Chen ${ }^{1}$, Long $\mathrm{Yi}^{4}$, Shiro Ikegawa ${ }^{5}$, Qing Jiang ${ }^{1,2^{*}}$

\begin{abstract}
Introduction: Developmental dysplasia of the hip $(\mathrm{DDH})$ is a common skeletal disease, which is characterized by abnormal seating of the femoral head in the acetabulum. Genetic factors play a considerable role in the etiology of DDH. Asporin (ASPN) is an ECM protein which can bind to TGF- $\beta 1$ and sequentially inhibit TGF- $\beta / S$ mad signaling. A functional aspartic acid (D) repeat polymorphism of ASPN was first described as an osteoarthritisassociated polymorphism. As TGF- $\beta$ is well known as an important regulator in the development of skeletal components, ASPN may also be involved in the etiology of DDH. Our objective is to evaluate whether the $\mathrm{D}$ repeat polymorphism of ASPN is associated with DDH in Han Chinese.

Methods: The D repeat polymorphism was genotyped in $370 \mathrm{DDH}$ patients and 445 control subjects, and the allelic association of the $D$ repeat was examined.

Results: From D11 to D18, eight alleles were identified. D13 allele is the most common allele both in control and DDH groups, the frequencies are $67.3 \%$ and $58.1 \%$ respectively. In the DDH group, a significantly higher frequency of the D14 allele and significantly lower frequency of D13 was observed. The association of D14 and D13 was found in both females and males after stratification by gender. There was no significant difference in any other alleles we examined.
\end{abstract}

Conclusions: Our results show an obvious association between the D repeat polymorphism of ASPN and DDH. It indicates that ASPN is an important regulator in the etiology of DDH.

\section{Introduction}

Developmental dysplasia of the hip (DDH; MIM $142700)$ is a common skeletal disease, which is characterized by abnormal seating of the femoral head in the acetabulum [1]. The incidence of DDH varies from 1 per 1,000 to 18.4 per 1,000 in the Caucasian population, and in the Chinese the incidence of DDH is about 4 per $1,000[1,2]$. DDH could lead to early onset of hip osteoarthritis because of increased contact pressure between the acetabulum and femoral head [3-5]. Shallow acetabulum and lax capsule were considered to be

\footnotetext{
* Correspondence: qingj@nju.edu.cn

+ Contributed equally

${ }^{1}$ The Center of Diagnosis and Treatment for Joint Disease, Drum Tower Hospital Affiliated to Medical School of Nanjing University, Zhongshan Road 321, Nanjing 210008, Jiangsu, PR China

Full list of author information is available at the end of the article
}

the main causes of DDH [6,7]. Several family studies indicated that a considerable genetic component played an important role in the etiology of DDH [8-10]. A genome-wide screening from a large four-generation Japanese family of acetabular dysplasia had revealed a linkage between DDH and a specific region at chromosome 13 [11]. We had detected a definite association between a functional SNP in GDF5 and DDH by a casecontrol study in the Chinese population, and this association was also found in Caucasians $[12,13]$.

Asporin (ASPN) is an ECM protein which belongs to the family of small leucine-rich repeat proteins [14]. Previous studies indicated that ASPN could bind to TGF- $\beta 1$ and block its interaction with the TGF- $\beta$ type II receptor, then sequentially inhibit the TGF- $\beta /$ Smad signaling and TGF- $\beta 1$ induced chondrogenesis $[15,16]$. 
TGF- $\beta 1$ was a crucial regulator for the perichondrial cells and fibroblast cells in tendons. Binding to TGF- $\beta 1$ may also inhibit perichondrium dependent skeletal development as well as development of tendons and ligaments $[17,18]$. ASPN can also bind to (bone morphogenetic protein 2) BMP2 and inhibit BMP/Smad signaling $[19,20]$. BMP2 is another growth factor of the TGF- $\beta$ family which plays a general role in differentiation and proliferation of perichondrial cells and osteoblast $[21,22]$.

Recently, an aspartic acid repeat polymorphism of $A S P N$ was first described as an osteoarthritis-associated polymorphism. The D14 allele of ASPN was over-represented in osteoarthritis subjects, and D14 allele showed greater inhibition of TGF- $\beta 1$ activity than the common allele, D13 [15]. This association was replicated in different populations and confirmed by meta-analysis although some studies denied this association [23-29]. This polymorphism was also identified to be associated with lumbar-disc degeneration and the outcome of rheumatoid arthritis [30,31].

As this polymorphism showed definite associations with various skeletal diseases [23-31], D14 allele and D13 allele of this polymorphism exhibited a remarkable difference in blocking TGF- $\beta /$ Smad signaling [15]. We suspected that this polymorphism may also play a pivotal role in the etiology and pathogenesis of DDH. To evaluate the possible association, we conducted a casecontrol study on ASPN with DDH in the Chinese Han population and found a compelling association between $A S P N$ and DDH.

\section{Materials and methods Subjects}

A total of 756 subjects were studied. Of these, 370 patients (313 females and 57 males) were enrolled at the Center of Diagnosis and Treatment for DDH, Kang'ai Hospital, while 445 healthy control subjects (290 females and 155 males) were enrolled at the Physical Examination Center, Drum Tower Hospital, affiliated to the Medical School of Nanjing University. All subjects studied in the study were Chinese Han living in and around Nanjing. No subjects dropped out during the process of the study. The study was approved by the ethical committee of the participating institutions, and informed consent was obtained from all subjects. Patients were diagnosed by expert medical examination with radiographic evidence, and they all suffered from unilateral or bilateral DDH. Severity of DDH was defined from mild instability of the femoral head with slight capsular laxity, through moderate lateral displacement of the femoral head, without loss of contact of the head with the acetabulum, up to complete dislocation of the femoral head from the acetabulum [32]. Control subjects were identified by detailed inquiry of history and physical examination, and they never had any history or symptoms of DDH. Subjects with any systemic syndrome were excluded from this study. The ages of patients and controls (mean \pm standard deviation (SD)) were $21.3 \pm 12.2$ (range, 2 to 51 ) months and $57.5 \pm$ 11.9 (range, 40 to 97 ) years, respectively. The ratio of female to male was about 6:1 in these cases.

\section{Genotyping}

Genomic DNA was extracted from peripheral blood using the Chelex-100 method or from buccal swabs using the DNA IQ System (Promega, Madison, WI, USA) according to the manufacturer's instructions [33]. DNA was genotyped for the ASPN microsatellite encoding the D repeat polymorphism after PCR amplification, the primers and thermal conditions were described before [23]. PCR products with $2 \mu \mathrm{L}$ STR $2 \times$ Loading Solution (Promega) were loaded onto 6\% denaturing polyacrylamide gel (BIO-RAD Sequi-Gen GT System 38 $\times 30 \mathrm{~cm}$, CAT. No.165-3862, Hercules, CA, USA). Samples were run at $50^{\circ} \mathrm{C}$ for about two hours. After electrophoresis, the gels were stained with silver nitrate. Allele size determination was carried out by comparison to an allele ladder.

\section{Statistical analysis}

Fisher's exact test was used to compare the ASPN genotype distribution in the case-control study. We assessed association and the Hardy-Weinberg equilibrium by the $\chi 2$ test. Odds ratio (OR), $P$-value and $95 \%$ confidence interval $(\mathrm{CI})$ were calculated with respect to the minor allele compared with the major allele. Stratification analyses by gender of DDH were performed using SPSS 12.0 system software (IBM SPSS, Chicago, IL, USA).

\section{Results}

Eight different alleles were identified, corresponding to 11 to $18 \mathrm{D}$ repeats (Table 1 ). There were 21 genotypes; distributions of genotypes in the DDH and control groups were conformed to Hardy-Weinberg equilibrium ( $P=0.723, P=0.179$, respectively). D13 was the most common allele in both patients and controls.

In the DDH group, the D14 allele had a significantly higher frequency and the D13 allele had a significantly lower frequency. A significant difference in the allelic frequency was observed in comparison of D14 versus (vs.) other alleles combined $(P=0.0016), \mathrm{D} 13$ vs. other alleles combined $\left(P=1.3^{*} 10^{-4}\right)$ and D14 vs. D13 $(P=$ $2.7^{*} 10^{-4}$ ) (Table 2). Considering eight alleles were tested (D11 to D18), then the Bonferroni corrected P-value should be 0.00625 . The significance remained after 
Table 1 Allelic frequency of the D-repeat polymorphism of ASPN in DDH in a Han Chinese population

\begin{tabular}{|c|c|c|c|c|c|c|c|c|c|c|}
\hline \multirow[t]{2}{*}{ Group } & \multirow[t]{2}{*}{ No. of subject } & \multicolumn{9}{|c|}{ No. of allele (\%) } \\
\hline & & $\overline{\mathrm{D} 11}$ & D12 & D13 & D14 & D15 & D16 & D17 & D18 & Total \\
\hline \multicolumn{11}{|l|}{$\overline{\mathrm{DDH}}$} \\
\hline All & 370 & $1(0.1)$ & $168(22.7)$ & $430(58.1)$ & $70(9.5)$ & $23(3.1)$ & $43(5.8)$ & $5(0.7)$ & 0 & 740 \\
\hline Female & 313 & $1(0.2)$ & $131(20.9)$ & $372(59.4)$ & $64(10.2)$ & $20(3.2)$ & $35(5.6)$ & $3(0.5)$ & 0 & 626 \\
\hline Male & 57 & 0 & 37 (32.4) & $58(50.8)$ & $6(5.2)$ & $3(2.6)$ & $8(7.0)$ & $2(1.8)$ & 0 & 114 \\
\hline \multicolumn{11}{|l|}{ CONTROL } \\
\hline All & 445 & 0 & $167(18.8)$ & $599(67.3)$ & $48(5.4)$ & $30(3.4)$ & $39(4.4)$ & $4(0.4)$ & $3(0.3)$ & 890 \\
\hline Female & 290 & 0 & $110(19.0)$ & $391(67.4)$ & $32(5.5)$ & $16(2.8)$ & $29(5.0)$ & $1(0.2)$ & $1(0.2)$ & 580 \\
\hline Male & 155 & 0 & 57 (18.3) & $208(67.1)$ & $16(5.1)$ & $14(4.5)$ & $103.2)$ & $3(1.0)$ & $2(0.6)$ & 310 \\
\hline
\end{tabular}

$A S P N$, aspirin; D-repeat, aspartic acid repeat; DDH, developmental dysplasia of the hip.

applying the Bonferroni correction. No significant differences were observed in any other alleles for comparisons of one allele vs. all the remaining alleles combined.

We stratified subjects by gender and compared the allelic frequency. In female subjects, significant differences were observed in a comparison of D14 vs. other alleles combined $(P=0.0025)$, D13 vs. other alleles combined $(P=0.004)$ and D14 vs. D13 $\left(P=9.3^{*} 10^{-4}\right)$ (Table $2)$. A significant difference was detected in comparison of D13 vs. the other alleles combined in males $(P=$ 0.002 ) (Table 2). The significance remained after applying the Bonferroni correction. No significance was found in other alleles for comparisons of one allele vs. all remaining alleles combined after stratification of gender.

\section{Discussion}

We have demonstrated $A S P N$ as a susceptibility gene of DDH with a case-control association study in Chinese Han population. D14 was identified as the risk allele; otherwise the common allele, D13, seemed to be a protective allele. Association was detected in both female and male subjects after stratification by gender.

A detailed analysis of ASPN expression in embryonic and adult mouse limbs showed that ASPN was expressed in perichondrium, periosteum, fascia, and tendon, but not in the articular cartilage and growth plate cartilage [34]. We considered that this polymorphism was not involved in the process of chondrocyte differentiation, although ASPN was demonstrated to inhibit chondrogenesis and chondrogenic differentiation via TGF- $\beta /$ Smad signaling in both mouse and human cell lines [16].

TGF- $\beta$ and BMP2 were crucial for the differentiation and proliferation of perichondrial cell and fibroblast cells $[17,18,21]$. Inhibition of TGF- $\beta /$ Smad and BMP2/ Smad signaling may reduce the differentiation and proliferation of perichondrial cells, and then delay the development of skeletal components; and it may also deduce the proliferation of fibroblast cells in tendon and fascia, and then loosen the tendon and fascia around a joint, which will make the joint easier to be dislocated.

D14 allele had a significant higher inhibitory effect on TGF- $\beta$ signaling [15], it may contribute to the susceptibility of DDH via one or both of these two mechanisms, defected soft tissues around hip joint and delayed skeletal development of the hip joint. On the other hand, the D13 allele had a significant weaker inhibition on TGF- $\beta$ signaling, so it exhibited a protective role in the pathogenesis of DDH.

\section{Conclusions}

Our study suggested an association of $A S P N$ with DDH susceptibility in a Chinese Han population, and ASPN is an important regulator in pathology of DDH. It may influence the susceptibility of DDH via TGF- $\beta$ signaling.

Table 2 Association of the D-repeat of ASPN in patients with DDH in a Han Chinese population

\begin{tabular}{|c|c|c|c|c|c|c|c|c|c|}
\hline \multirow[t]{2}{*}{ Groups compared } & \multicolumn{3}{|c|}{ D14 vs. Others } & \multicolumn{3}{|c|}{ D13 vs. Others } & \multicolumn{3}{|c|}{ D14 vs. D13 } \\
\hline & OR & $P$-value & $95 \% \mathrm{Cl}$ & OR & $P$-value & $95 \% \mathrm{Cl}$ & OR & $P$-value & $95 \% \mathrm{Cl}$ \\
\hline $\begin{array}{l}\text { All patients }(n=370) \text { vs. } \\
\text { All controls }(n=445)\end{array}$ & 1.83 & 0.0016 & 1.25 to 2.68 & 0.67 & $1.3^{*} 10^{-4}$ & 0.55 to 0.82 & 2.03 & $2.7^{*} 10^{-4}$ & 1.38 to 2.99 \\
\hline $\begin{array}{l}\text { Female patients }(n=313) \text { vs. } \\
\text { Female controls }(n=290)\end{array}$ & 1.95 & 0.0025 & 1.26 to 3.03 & 0.71 & 0.004 & 0.56 to 0.90 & 2.10 & $9.3^{*} 10^{-4}$ & 1.34 to 3.29 \\
\hline $\begin{array}{l}\text { Male patients }(n=57) \text { vs. } \\
\text { Male controls }(n=155)\end{array}$ & 1.02 & 0.96 & 0.39 to 2.68 & 0.51 & 0.002 & 0.33 to 0.79 & 1.34 & 0.55 & 0.50 to 3.59 \\
\hline
\end{tabular}

ASPN, asporin; $\mathrm{Cl}$, confidence interval; D-repeat, aspartic acid repeat; $\mathrm{DDH}$, developmental dysplasia of the hip; OR, odds ratio. 


\section{Abbreviations}

ASPN: asporin; BMP2: bone morphogenetic protein 2; D: aspartic acid; DDH: developmental dysplasia of the hip; TGF- $\beta$ : transforming growth factor- $\beta$.

\section{Acknowledgements}

This work was supported by the National Nature Science Foundation of China (30901570) (to D.S, X.Q and Q.J)

\section{Author details}

${ }^{1}$ The Center of Diagnosis and Treatment for Joint Disease, Drum Tower Hospital Affiliated to Medical School of Nanjing University, Zhongshan Road 321, Nanjing 210008, Jiangsu, PR China. ${ }^{2}$ Laboratory for Bone and Joint Diseases, Model Animal Research Center, Nanjing University, Xuefu Road 12, Nanjing 210008, Jiangsu, PR China. ${ }^{3}$ Center of Diagnosis and Treatment for Congenital Dysplasia of Hip, Kang'ai Hospital, Nanchang Road 32, Nanjing 210008, Jiangsu, PR China. ${ }^{4}$ Department of Pathology, Medical School of Nanjing University, Hankou Road 22, Nanjing 210093, Jiangsu, PR China. ${ }^{5}$ Laboratory for Bone and Joint Diseases, Center for Genomic Medicine, RIKEN, 4-6-1 Shirokanedai, Minato-ku, Tokyo 108-8639, Japan.

\section{Authors' contributions}

All authors contributed to the final manuscript. In addition, DS and JD genotyped the samples and participated in the design and analysis of the study. PZ, JQ, LZ, HZ, BZ, XQ, ZX and DC evaluated the patients and genotyped these samples. LY and SI coordinated the study. QJ supervised the whole study.

\section{Competing interests}

The authors declare that they have no competing interests.

Received: 11 December 2010 Revised: 1 February 2011

Accepted: 17 February 2011 Published: 17 February 2011

\section{References}

1. Sollazzo V, Bertolani G, Calzolari E, Atti G, Scapoli C: A two-locus model for non-syndromic congenital dysplasia of the hip (CDH). Ann Hum Genet 2000, 64:51-59.

2. Laurence M, Harper PS, Harris R, Nevin NC, Roberts DF: Report of the delegation of clinical geneticists to China, Spring 1986. Biol Soc 1987, 4:61-77.

3. Hartofilakidis G, Karachalios T, Stamos KG: Epidemiology, demographics, and natural history of congenital hip disease in adults. Orthopedics 2000, 23:823-827.

4. Hasegawa Y, Iwata H, Mizuno M, Genda E, Sato S, Miura T: The natural course of osteoarthritis of the hip due to subluxation or acetabular dysplasia. Arch Orthop Trauma Surg 1992, 111:187-191.

5. Russell ME, Shivanna KH, Grosland NM, Pedersen DR: Cartilage contact pressure elevations in dysplastic hips: a chronic overload model. J Orthop Surg Res 2006, 1:6.

6. Wilkinson J, Carter C: Congenital dislocation of the hip: the results of conservative treatment. J Bone Joint Surg Br 1960, 42:669-688.

7. Carter C, Wilkinson J: Persistent joint laxity and congenital dislocation of the hip. J Bone Joint Surg Br 1964, 46:40-45.

8. Kramer AA, Berg K, Nance WE: Familial aggregation of congenital dislocation of the hip in a Norwegian population. J Clin Epidemiol 1988, 41:91-96.

9. Czeizel A, Szentpetery J, Tusnady G, Vizkelety T: Two family studies on congenital dislocation of the hip after early orthopaedic screening Hungary. J Med Genet 1975, 12:125-130.

10. Geiser M, Buri B, Buri P: Congenital dislocation of the hip in identical twins. J Bone Joint Surg Br 1959, 41:314-318.

11. Mabuchi A, Nakamura S, Takatori Y, Ikegawa S: Familial osteoarthritis of the hip joint associated with acetabular dysplasia maps to chromosome 13q. Am J Hum Genet 2006, 79:163-168.

12. Dai J, Shi D, Zhu P, Qin J, Ni H, Yao C, Zhu L, Zhao B, Wei J, Liu B, Ikegawa $S$, Jiang $Q$, Ding $Y$ : Association of a single nucleotide polymorphism in growth differentiate factor 5 with congenital dysplasia of the hip: a case-control study. Arthritis Res Ther 2008, 10:R126.

13. Rouault K, Scotet V, Autret S, Gaucher F, Dubrana F, Tanguy D, El Rassi CY, Fenoll B, Férec C: Evidence of association between GDF5 polymorphisms and congenital dislocation of the hip in a Caucasian population. Osteoarthritis Cartilage 2010, 18:1144-1149.
14. Lorenzo P, Aspberg A, Onnerfjord P, Bayliss MT, Neame PJ, Heinegard D: Identification and characterization of asporin, a novel member of the leucine-rich repeat protein family closely related to decorin and biglycan. J Biol Chem 2001, 276:12201-12211.

15. Kizawa H, Kou I, lida A, Sudo A, Miyamoto Y, Fukuda A, Mabuchi A, Kotani A, Kawakami A, Yamamoto S, Uchida A, Nakamuna K, Notoya K, Nakamura Y, Ikegawa S: An aspartic acid repeat polymorphism in asporin inhibits chondrogenesis and increases susceptibility to osteoarthritis. Nat Genet 2005, 37:138-144.

16. Nakajima M, Kizawa H, Saitoch M, Kou I, Miyazono K, Ikegawa S: Mechanisms for asporin function and regulation in articular cartilage. J Biol Chem 2007, 282:32185-32192.

17. Silverio-Ruiz KG, Martinez AE, Garlet GP, Barbosa CF, Silva JS, Cicarelli RM, Valentini SR, Abi-Rached RS, Junior CR: Opposite effects of bFGF and TGFbeta on collagen metabolism by human periodontal ligament fibroblasts. Cytokine 2007, 39:130-137.

18. Okamoto S, Tohyama H, Kondo E, Anaguchi Y, Onodera S, Hayashi K, Yasuda K: Ex vivo supplementation of TGF-beta1 enhances the fibrous tissue regeneration effect of synovium-derived fibroblast transplantation in a tendon defect: a biomechanical study. Knee Surg Sports Traumatol Arthrosc 2008, 16:333-339.

19. Yamada S, Tomoeda M, Ozawa Y, Yoneda S, Terashima Y, Ikezawa K, Ikegawa S, Saito M, Toyosawa S, Murakami S: PLAP-1/asporin, a novel negative regulator of periodontal ligament mineralization. $J$ Biol Chem 2007, 282:23070-23080

20. Tomoeda M, Yamada S, Shirai H, Ozawa Y, Yanagita M, Murakami S: PLAP1/asporin inhibits activation of BMP receptor via its leucine-rich repeat motif. Biochem Biophys Res Commun 2008, 371:191-196.

21. Samee M, Kasugai S, Kondo H, Ohya K, Shimokawa H, Kuroda S: Bone morphogenetic protein-2 (BMP-2) and vascular endothelial growth factor (VEGF) transfection to human periosteal cells enhances osteoblast differentiation and bone formation. J Pharmacol Sci 2008, 108:18-31.

22. Lecanda F, Avioli LV, Cheng SL: Regulation of bone matrix protein expression and induction of differentiation of human osteoblasts and human bone marrow stromal cells by bone morphogenetic protein- 2 . J Cell Biochem 1997, 67:386-396.

23. Jiang Q, Shi D, Yi L, lkegawa S, Wang Y, Nakamura T, Qiao D, Liu C, Dai J: Replication of the association of the aspartic acid repeat polymorphism in the asporin gene with knee-osteoarthritis susceptibility in Han Chinese. J Hum Genet 2006, 51:1068-1072.

24. Valdes AM, Loughlin J, Oene MV, Chapman K, Surdulescu GL, Doherty M, Spector TD: Sex and ethnic differences in the association of ASPN, CALM1, COL2A1, COMP, and FRZB with genetic susceptibility to osteoarthritis of the knee. Arthritis Rheum 2007, 56:137-146.

25. Shi D, Nakamura T, Dai J, Yi L, Qin J, Chen D, Xu Z, Wang Y, Ikegawa S, Jiang Q: Association of the aspartic acid-repeat polymorphism in the asporin gene with age at onset of knee osteoarthritis in Han Chinese population. J Hum Genet 2007, 52:664-667.

26. Song JH, Lee HS, Kim CJ, Cho YG, Park YG, Nam SW, Lee JY, Park WS: Aspartic acid repeat polymorphism of the asporin gene with susceptibility to osteoarthritis of the knee in a Korean population. Knee 2008, 15:191-195.

27. Nakamura T, Shi D, Tzetis M, Rodigiez-Lopex J, Miyamoto Y, Tsezou A, Gonzalez A, Jiang Q, Kamatani N, Loughlin J, Ikegawa S: Meta-analysis of association between the ASPN D-repeat and osteoarthritis. Hum Mol Genet 2007, 16:1676-1681.

28. Rodriguez-Lopez J, Pombo-Suarez M, Liz M, Gomez-Reino JJ, Gonzalez A: Lack of association of a variable number of aspartic acid residues in the asporin gene with osteoarthritis susceptibility: case-control studies in Spanish Caucasians. Arthritis Res Ther 2006, 8:R55.

29. Atif U, Philip A, Aponte J, Woldu EM, Brady S, Kraus VB, Jordan JM, Doherty M, Wilson AG, Moskowitz RW, Hochberg M, Loeser R, Renner JB, Chiano M: Absence of association of asporin polymorphisms and osteoarthritis susceptibility in US Caucasians. Osteoarthritis Cartilage 2008, 16:1174-1177.

30. Song YQ, Cheung KM, Ho DW, Poon SC, Chiba K, Kawaguchi Y, Hirose $Y$, Alini M, Grad S, Yee AF, Leong JC, Luk KD, Yip SP, Karppinen J, Cheah KS, Sham P, Ikegawa S, Chan D: Association of the asporin D14 allele with lumbar-disc degeneration in Asians. Am J Hum Genet 2008, 82:744-747.

31. Torres B, Orozco G, García-Lozano JR, Oliver J, Fernández O, GonzálezGay MA, Balsa A, García A, Pascual-Salcedo D, López-Nevot MA, 
Núñez-Roldán A, Martín J, González-Escribano MF: Asporin repeat polymorphism in rheumatoid arthritis. Ann Rheum Dis 2007, 66:118-120.

32. Sherk HH, Pasquariello PS Jr, Watters WC: Congenital dislocation of the hip. A review. Clin Pediatr (Phila) 1981, 20:513-520.

33. Walsh PS, Metzger DA, Higuchi R: Chelex 100 as a medium for simple extraction of DNA for PCR-based typing from forensic material. Biotechniques 1991, 10:506-513.

34. Kou Ikuyo, Nakajima Masahiro, Ikegawa Shiro: Expression and Regulation of the Osteoarthritis-associated Protein Asporin. J Biol Chem 2007, 282:32193-32199.

doi:10.1186/ar3252

Cite this article as: Shi et al: Association of the D repeat polymorphism in the ASPN gene with developmental dysplasia of the hip: a casecontrol study in Han Chinese. Arthritis Research \& Therapy 2011 13:R27.

Submit your next manuscript to BioMed Central and take full advantage of:

- Convenient online submission

- Thorough peer review

- No space constraints or color figure charges

- Immediate publication on acceptance

- Inclusion in PubMed, CAS, Scopus and Google Scholar

- Research which is freely available for redistribution

Submit your manuscript at www.biomedcentral.com/submit 